\title{
Swelling of Iron Ore Pellets During Reduction*
}

\author{
By Tasuku FUWA $A^{* *}$ and Shiro BAN-YA**
}

\section{Synopsis}

The extraordinary swelling of iron ore pellets during reduction was analy zed in a controlled $\mathrm{CO}-\mathrm{CO}_{2}$ mixture at temperature from $600^{\circ}$ to $1200^{\circ} \mathrm{C}$. In addition to the iron ore pellets, the pelletizing feed, several kinds of iron ore, and reagent grade ferric oxides were reduced under the same condition as the pellets.

Most of swelling takes place in the stage of reduction from wüstite to metallic iron. The apparent volume change is related to the appearance of fibrous iron as the reduction preduct.

\section{Introduction}

For the Japanese blast furnace which has increased her productivity by charging self-fluxing sinters, it has come into question whether iron ore pellets as the charging material for a blast furnace will have more advantages than sintered iron ore in the near future.

However, the first trial to charge iron ore pellets, imported from the Marcona Mining Company, to a blast furnace did not succeed as well as expected to improve operation and productivity. It was a problem to be solved promptly. So far it was disclosed phenomenally that during reduction pellets expanded and took powder form, and were not strong enough as blast furnace burden. The cause of swelling of Marcona pellets has been discussed as due to carbon deposition or formation of $\gamma$-hematite. ${ }^{1)}$ Watanabe and Yoshinaga $^{2)}$ suggested the appearance of fibrous iron from wüstite to be related to the extraordinary swelling of the Marcona pellets. Matoba and Otake $^{3)}$ observed previously fibrous metallic iron in

reduced iron ores.

This paper will clarify the mechanism of swelling of iron ores, whose characteristic is not limited to the Marcona pellets. In other words, in general, pure iron oxide swells in the step from wüstite to metallic iron in process of reduction and becomes fibrous metallic iron under certain conditions.

\section{Experimental Apparatus}

The experimental apparatus for this work consists of the train for purification of $\mathrm{CO}$, which was prepared from formic acid and concentrated sulphuric acid; the train for purification of $\mathrm{CO}_{2}$ from a cylinder (if necessary, this train was used for hydrogen instead of $\left.\mathrm{CO}_{2}\right)$; the train for purification of argon from a cylinder by controlling flowrates of these gases, desired gas mixture could be supplied to the reaction tube. The reaction tube, which was made of a silica tube with $55 \mathrm{~mm}$ outer diameter and suited to be heated up to $1300^{\circ} \mathrm{C}$. During the course of this work, the reaction tube, shown in Fig. 2, was used for determination of bulk expansion of a pellet, instead of $\mathrm{H}$ in Fig. 1 . The reaction tube is also made of a silica tube with $30 \mathrm{~mm}$ outer diameter. A pellet was set in a nickel crucible with a many-holed bottom. A concave nickel plate was put on the pellet upside-down. A $2 \mathrm{~mm}$ silica rod was attached to the nickel plate. Therefore, if the pellet expands during reduction, its expansion is measured by reading the top of the silica rod by means of a cathetometer. However, a pellet does not always

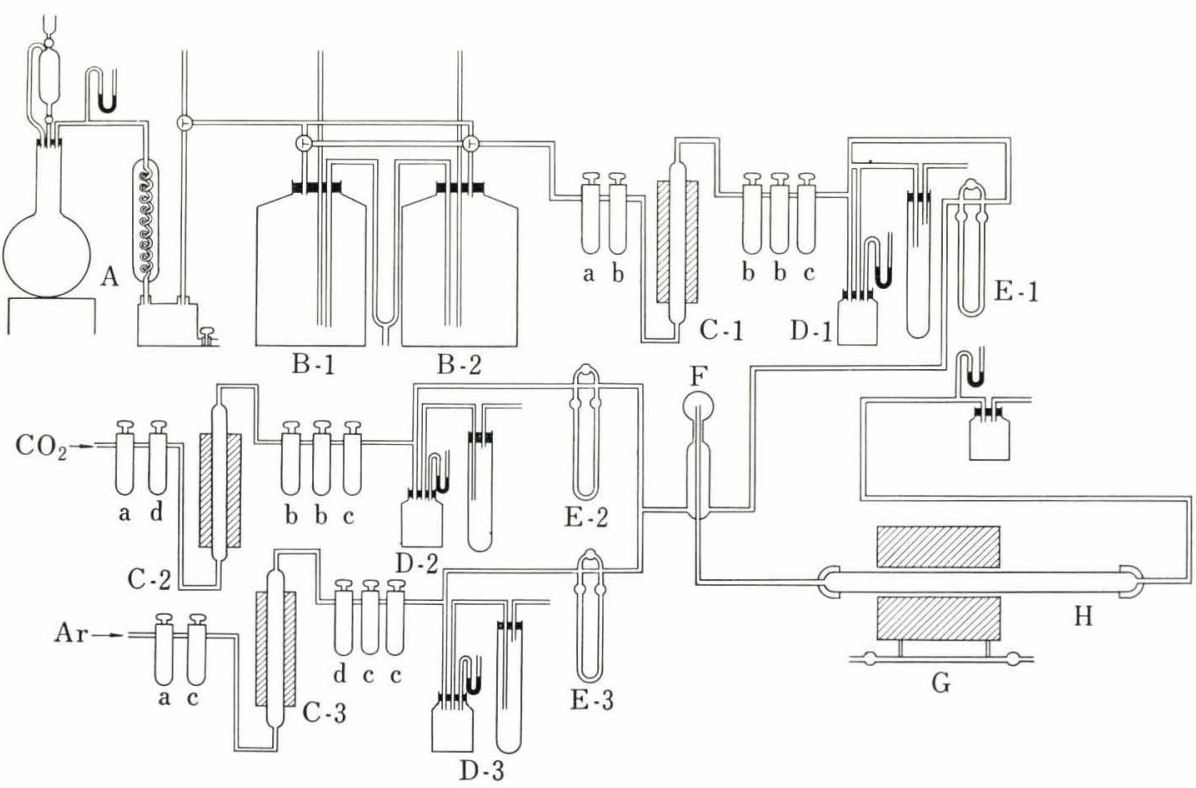

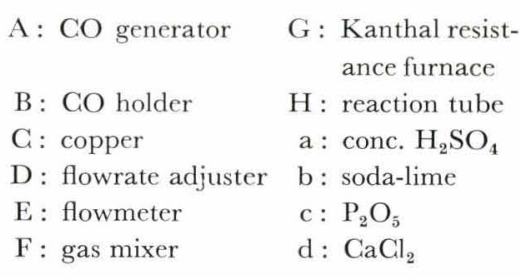

Fig. 1. Experimental apparatus

* Presented at Joint Symposium of USSR and Japan on Physical Chemistry of Metallurgical Processes, in Moscow, May, 1967. Manuscript received August 22, 1968.

** Department of Metallurgy, Faculty of Engineering, Tohoku University, Sendai 980. 
expand uniformly, rather it expands irregularly, and even the concave nickel plate disturbs its free expansion. Therefore, in order to measure the bulk expansion of the pellet, a nickel cup was designed as shown in Fig. 3. Instead of a vertical reaction tube, a horizontal reaction tube as shown in Fig. 1, was applied to the "cup test."

\section{Experimental Procedure}

Iron ore pellets used for this work are a part of pellets shipped by the first boat from Marcona Mining Company and were chosen for comparatively spherical form of diameter $14 \sim 16 \mathrm{~mm}$. The chemical composition of the pellets is shown in Table 1. They were heated previously to dry in the air at $500^{\circ} \mathrm{C}$ and have been kept in a desiccator.

One pellet was taken for making a run, weighed, and measured in diameter at four places with the average taken as the pellet diameter. The pellet in the nickel crucible was set in the reaction tube, and the experimental train was replaced by argon with the flowrate $100 \mathrm{cc} / \mathrm{min}$. Then the furnace, previously heated to a given temperature, was made hotter to heat the reac-

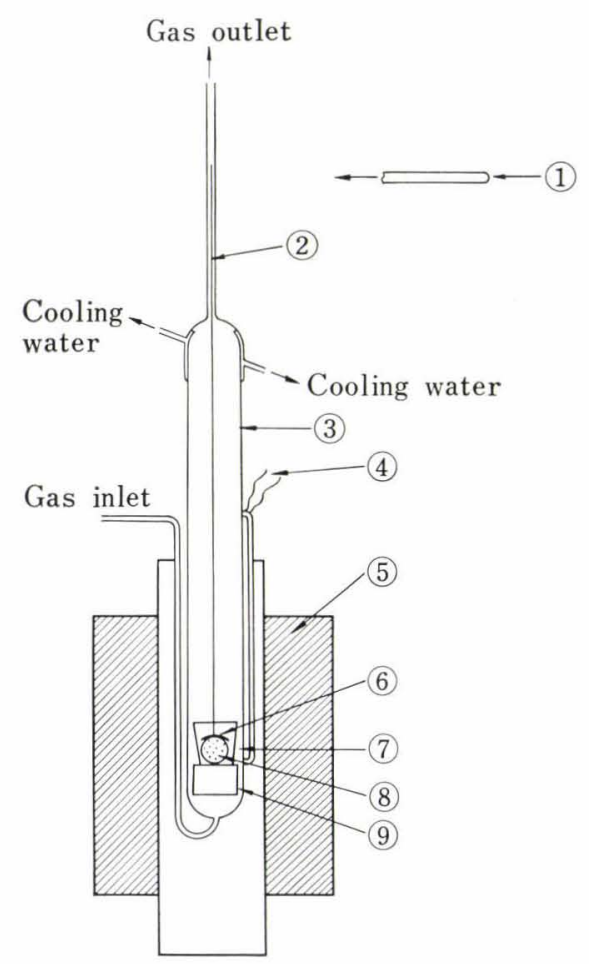

(1) Cathetometer

(2) Silica glass rod

(3) Reaction tube

(4) Thermocouple

(5) SiC resistance furnace
(6) Conical nickel plate

(7) Nickel crucible

(8) Iron ore pellet

(9) Alumina tube supporter
Fig. 2. Reaction tube tion tube. After the temperature became steady at a given temperature, argon stream was switched to reducing gas with the flowrates 100 and $200 \mathrm{cc} / \mathrm{min}$. Then the temperature and expansion were observed every $10 \mathrm{~min}$ for $4 \mathrm{hr}$. As the reducing gas, $\mathrm{CO}$, $\mathrm{H}_{2}$, CO- $\mathrm{CO}_{2}$ mixture, and $\mathrm{H}_{2}$-propane mixture were used at temperatures from $600^{\circ}$ to $1200^{\circ} \mathrm{C}$. Then the reaction tube was cooled in the argon stream to room temperature. The pellet after reduction was weighed and its diameter at four different places was measured again. Bulk expansion will be given as follows :

$$
\text { Bulk expansion } \begin{aligned}
(\%) & =\text { Apparent volume change }(\%) \\
& \left.=\left(V_{a}-V_{i}\right) / V_{i} \times 100 \ldots \ldots \ldots \ldots . . .11\right)
\end{aligned}
$$

where, $V_{a}$ is the volume of a pellet after reduction, and $V_{i}$ is the initial volume of a pellet before reduction.

The nickel cup test was applied, based on the results obtained by the above mentioned experimental procedure, in order to clarify the relationship between deformation of iron ore particles and degree of swelling during reduction. Several different sizes of cups were prepared; as far as the cup of dimensions shown in Fig. 3 is concerned, one with an inner volume of about $4 \mathrm{~cm}^{3}$ was used and the result of the cup test gave a good reproducibility. For the cup test, not only the Marcona pellet but also the Marcona pelletizing feed was used, with chemical composition as shown in Table 1. And the screen analysis of the pelletizing feed is shown in Fig. 4 and Table 2.

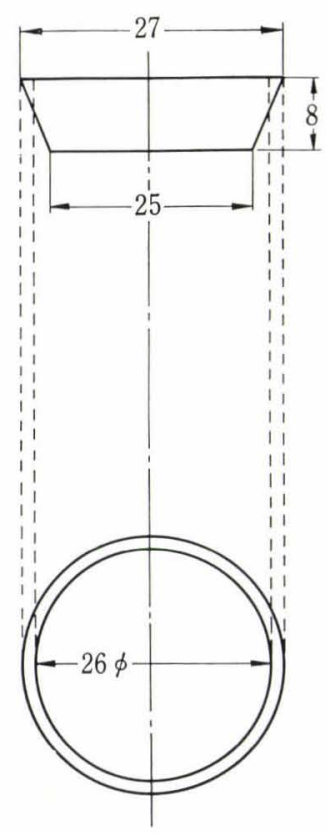

Fig. 3. Nickel cup ( $\mathrm{mm})$

\begin{tabular}{|c|c|c|c|c|c|c|c|c|c|c|c|c|c|c|}
\hline & T.Fe & $\mathrm{FeO}$ & $\mathrm{Fe}_{2} \mathrm{O}_{3}$ & $\mathrm{SiO}_{2}$ & $\mathrm{CaO}$ & $\mathrm{Al}_{2} \mathrm{O}_{3}$ & $\mathrm{MgO}$ & $\mathrm{MnO}$ & $\mathrm{TiO}_{2}$ & $\mathrm{Cu}$ & $\mathrm{P}$ & $\mathrm{S}$ & $\mathrm{Ni}$ & Cr \\
\hline Pellet $A$ & 67.78 & 1.09 & 95.69 & 0.85 & 0.11 & 0.25 & 0.32 & 0.04 & 0.006 & 0.029 & 0.012 & 0.012 & 0.012 & 0.004 \\
\hline
\end{tabular}

Table 1. The chemical composition of Marcona pellet and the pelletizing feed 
The experimental procedure of the cup test was just the same as mentioned above, except for use of the nickel cup in a horizontal reaction tube instead of a vertical one.

For the pelletizing feed, about $10 \mathrm{~g}$ feed was filled in a nickel cup. After reduction, the bulk expansion of a reduced sample was calculated from the shape, the average diameter and height of expanded feed being measured.

\section{Experimental Results}

In Fig. 5, some typical curves of the vertical diameter charge plotted against time, are shown. For the first $10 \mathrm{~min}$ the vertical diameter change was not large, but was followed by rapid increase, and then stayed at a constant value. However, as mentioned above, a pellet does not swell uniformly. Even concave nickel plate disturbs the free expansion of a pellet. Therefore, apparent volume change was calculated from the diameter of the comparatively spherical swollen pellet.

In Fig. 6, apparent volume changes during the reduction of the Marcona and Erie pellets was compared. The Erie pellet shows a maximum 15\% volume increase, while the Marcona pellet shows about $280 \%$ volume change. Both curves for Marcona pellets in Figs. 5 and 6 show a steep increase after 30 or $40 \mathrm{~min}$ of reduction, which is related to the reaction from $\mathrm{FeO}$ to metallic iron.

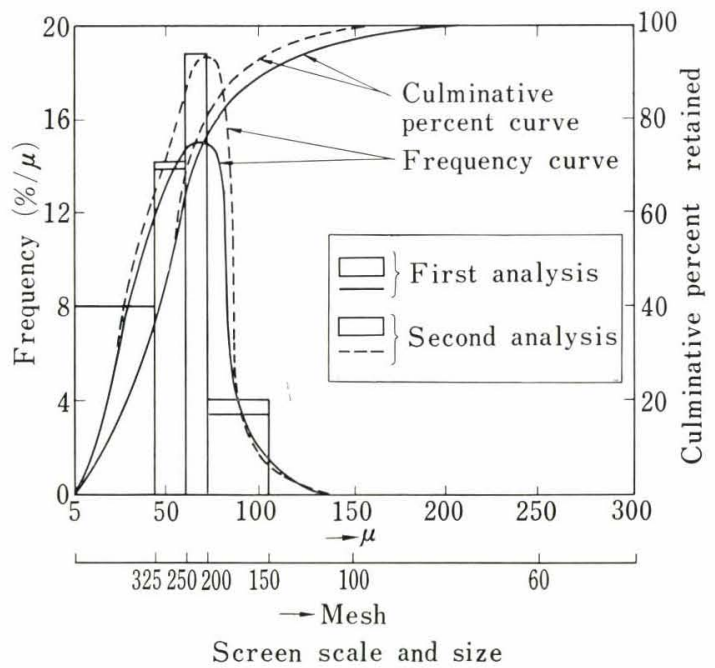

Fig. 4. Screen analysis for Marcona pelletizing feed

Table 2. Screen analysis for Marcona pelletizing feed

\begin{tabular}{c|c|c}
\hline $\begin{array}{c}\text { Screen scale } \\
\text { (Mesh) }\end{array}$ & $\begin{array}{c}\text { 1st analysis } \\
(\%)\end{array}$ & $\begin{array}{c}\text { 2nd analysis } \\
(\%)\end{array}$ \\
\hline+60 & 0.2 & 0.1 \\
60 to 100 & 2.2 & 0.4 \\
100 to 150 & 5.8 & 5.6 \\
150 to 200 & 12.6 & 10.5 \\
200 to 250 & 18.0 & 22.5 \\
250 to 325 & 25.0 & 25.6 \\
-325 & 36.2 & 35.4 \\
\hline
\end{tabular}

Sample taken : $500 \mathrm{~g}\left(\right.$ dried at $\left.120^{\circ} \mathrm{C}\right)$

JIS Screen : $5 \mathrm{hr}$
In Fig. 7, the apparent volume change of the pellet was shown when a pellet was reduced in the following reducing gases at temperatures from $600^{\circ}$ to $1200^{\circ} \mathrm{C}: \mathrm{CO}$ and $\mathrm{H}_{2}$ reduce a pellet to metallic iron; $50 \% \mathrm{CO}-50 \% \mathrm{CO}_{2}$ mixture reduces to wüstite ("FeO"); $90 \% \mathrm{CO}_{2}-10 \% \mathrm{CO}$ mixture reduces to

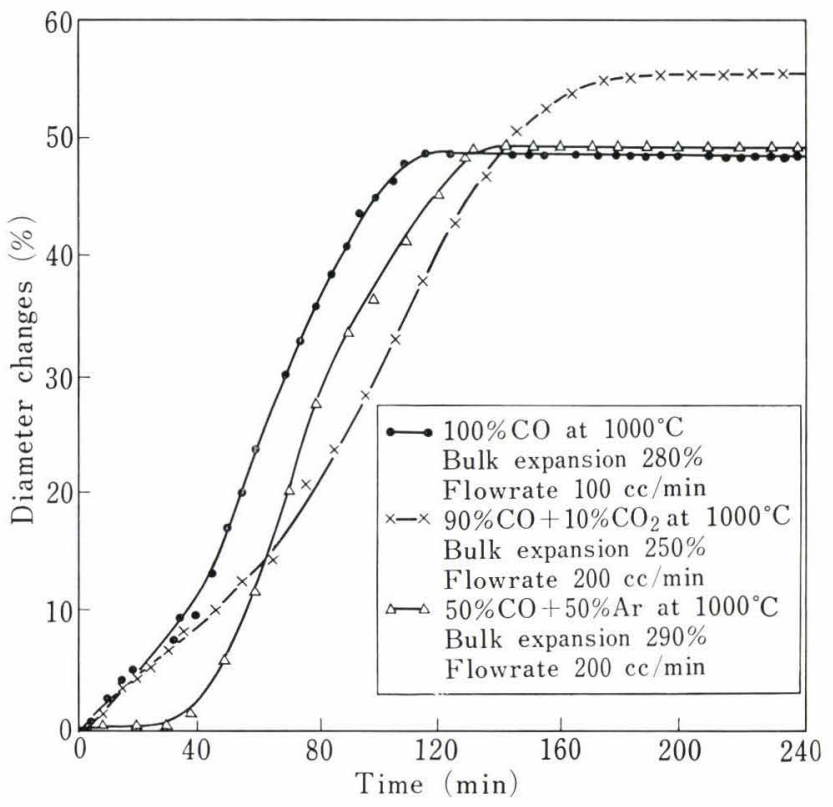

Fig. 5. Diameter changes of Marcona pellet in process of reduction

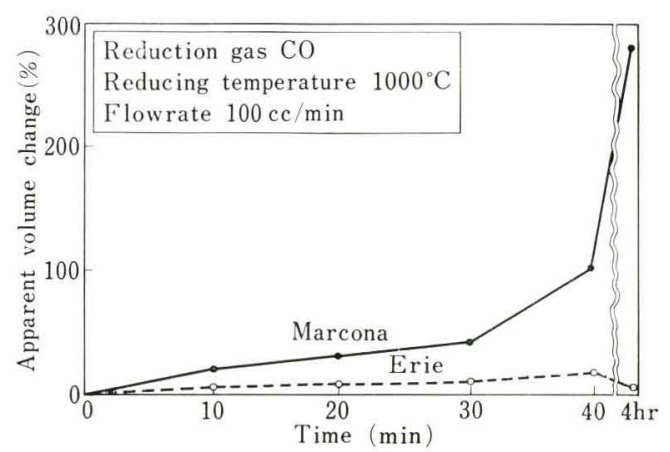

Fig. 6. Volume change of pellet in process of reduction

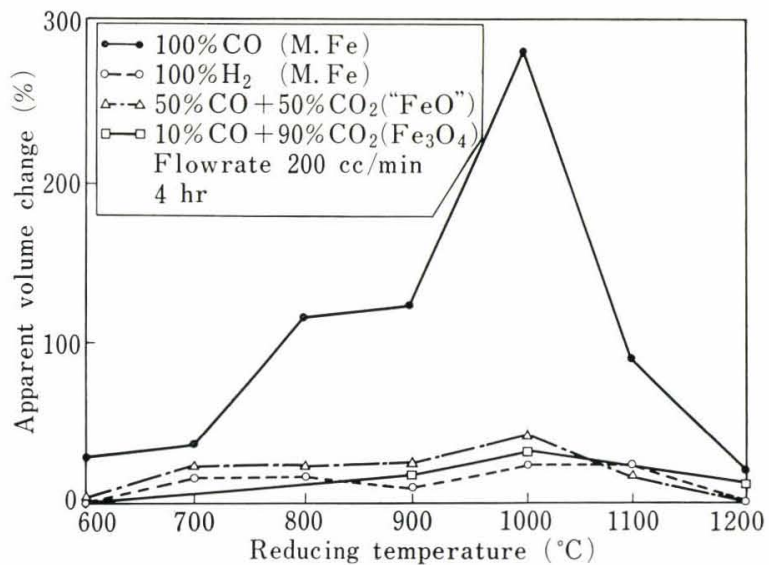

Fig. 7. Relation between temperature and apparent volume change 
$\mathrm{Fe}_{3} \mathrm{O}_{4}$. There was about a $20 \%$ increase in the apparent volume change of a pellet which was reduced to metallic iron in the hydrogen stream. The maximum volume change was observed at $1000^{\circ} \mathrm{C}$. At a temperature higher than $600^{\circ} \mathrm{C}, \mathrm{Fe}_{2} \mathrm{O}_{3}$ is reduced to metallic iron through the stages of $\mathrm{Fe}_{3} \mathrm{O}_{4}$ and "FeO." Therefore, by controlling the ratio of carbon monoxide to carbon dioxide, the Marcona pellet was reduced in a given gas mixture for $4 \mathrm{hr}$ at $1000^{\circ} \mathrm{C}$, at which the maximum volume change was observed. The results obtained are shown in Fig. 8, which clearly shows that a large part of the extraordinary swelling of the Marcona pellet takes place in the stage in which "FeO" is reduced to metallic iron. In the ranges of $\mathrm{Fe}_{3} \mathrm{O}_{4}$ and "FeO," the volume change increases with higher $\mathrm{CO}$-mixtures and was at a maximum at 15 and $20 \sim 35 \%$ respectively. In the $\mathrm{CO}-\mathrm{CO}_{2}$ mixture equilibrated with stable $\mathrm{Fe}_{3} \mathrm{O}_{4}$ or " $\mathrm{FeO}$ " at $1000^{\circ} \mathrm{C}$, the reaction of carbon deposition does not occur. Nevertheless the fact that a $15 \sim 35 \%$ swelling was observed in the magnetite and wüstite range, shows that swelling is not directly caused by carbon deposition, as will be explained later.

In order to check the effect of the rate of reduction on the apparent volume change, a pellet was reduced at $1000^{\circ} \mathrm{C}$ in the $\mathrm{CO}$-stream with 50,100 , and $200 \mathrm{cc} /$ min for $4 \mathrm{hr}$, but it was not found to change phenomenally. Therefore, in order to reduce it further, the $\mathrm{CO}$-argon mixture with $200 \mathrm{cc} / \mathrm{min}$, in which 5, 10, and $15 \% \mathrm{CO}$ was mixed, was applied to reduce a pellet at $1000^{\circ} \mathrm{C}$. The results obtained are shown in Fig. 9. A higher mixture than $15 \% \mathrm{CO}$ does not affect reduction much differently from 100\%CO. However, a lower $\mathrm{CO}$-mixture shows lower volume increase. In order to make sure the effect of the carbon deposition on the swelling, the carbon content of the reduced pellet was determined as shown in Table 3 and Fig. 9. A hydrogen-propane mixture was also used to reduce the pellet for $4 \mathrm{hr}$ at $1000^{\circ} \mathrm{C}$. From these results it can be seen that the carbon deposition is not directly related to the cause of swelling. Also it was clarified that the swelling of the pellets is caused by the lowering of the bulk density, and it is not like volume expansion of the metal caused by lowering its true density.

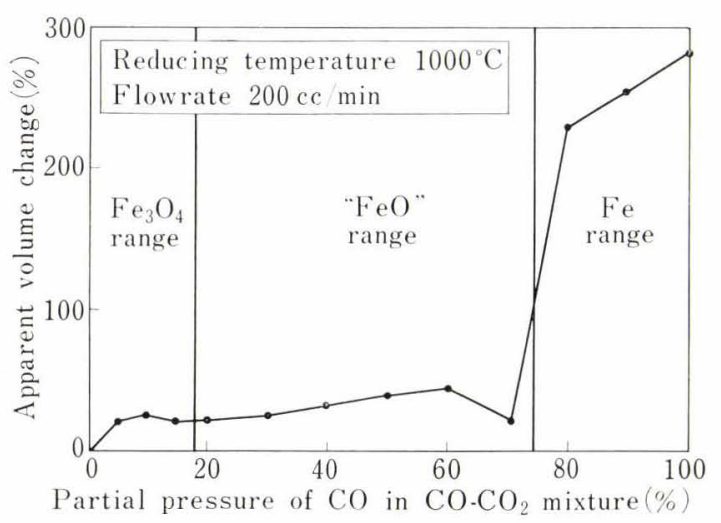

Fig. 8. Effect of the gas composition of $\mathrm{CO}-\mathrm{CO}_{2}$ mixture on the apparent volume change
However, extraordinary swelling did not occur in the Erie pellets. Therefore, in order to ascertain whether it is a characteristic phenomenon of the Marcona pellets, or whether it is related to the origin or occurrence of the iron ore, the cup test was applied to the Marcona pellet and pelletizing feed in 100 $200 \mathrm{cc} / \mathrm{min} \mathrm{CO}$-stream at $600^{\circ} \sim 1200^{\circ} \mathrm{C}$ for $4 \sim$ $5 \mathrm{hr}$. The results obtained are shown in Fig. 10 and Photo. 1. Photograph 2 is a microscopic picture of the pelletizing feed before reduction, and Photos. 3 11 are the pictures of a part of the reduced pelletizing feed and pellets taken through microscopy. These pictures show the apparent change of the shape of the initial grains. According to the cup test, the pelletizing feed swells most between $800^{\circ} \sim 1000^{\circ} \mathrm{C}$, the biggest swelling taking place at $900^{\circ} \mathrm{C}$, while it occurs at $1000^{\circ} \mathrm{C}$ in pellets. At $1100^{\circ} \sim 1200^{\circ} \mathrm{C}$, the tend-

Table 3. Carbon content in reduced pellet

\begin{tabular}{cccc}
$\begin{array}{c}\text { Reducing } \\
\text { gas }\end{array}$ & $\begin{array}{c}\text { Temperature } \\
\left({ }^{\circ} \mathrm{C}\right)\end{array}$ & $\begin{array}{c}\text { Carbon } \\
\text { content } \\
(\%)\end{array}$ & $\begin{array}{c}\text { Apparent } \\
\text { volume change } \\
(\%)\end{array}$ \\
\hline $100 \% \mathrm{CO}$ & 1000 & 0.09 & 280 \\
$100 \% \mathrm{CO}$ & 600 & 3.30 & 30 \\
$50 \% \mathrm{CO}$ & 1000 & 0.01 & 39 \\
$50 \% \mathrm{CO}_{2}$ & & & 4.2 \\
$50 \% \mathrm{CO}^{5}$ & 600 & 0.02 & \\
\hline $\mathrm{CO}_{2}$ & & & \\
\hline
\end{tabular}

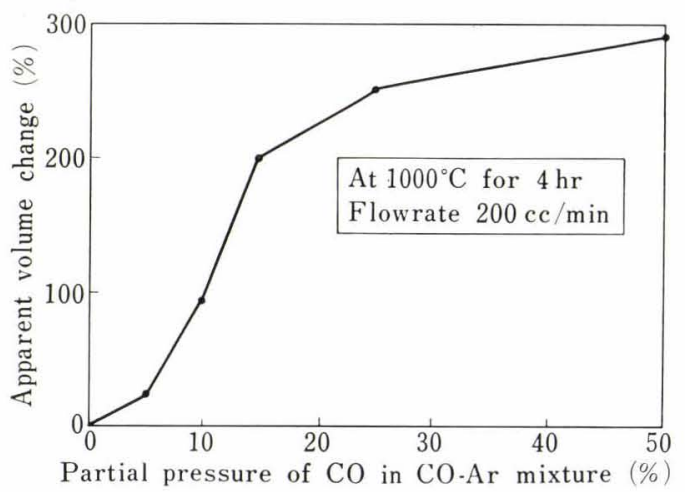

Fig. 9. Effect of rate of reduction on apparent volume change

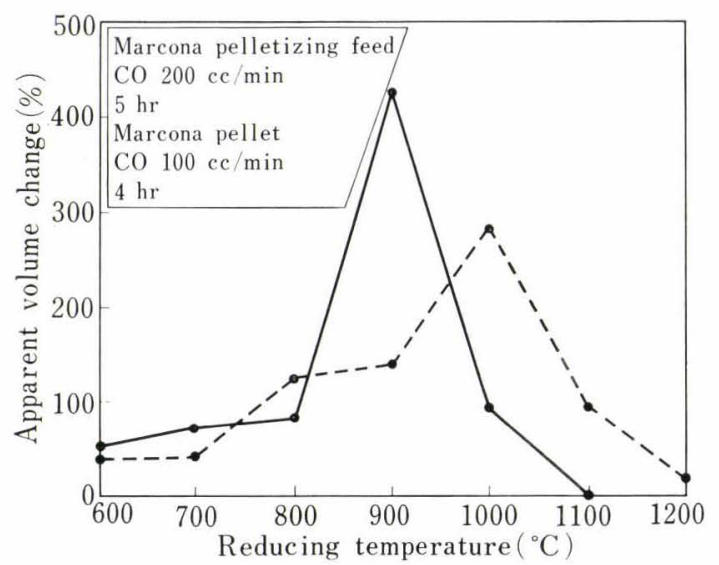

Fig. 10. Effect of reducing temperature on apparent volume change 


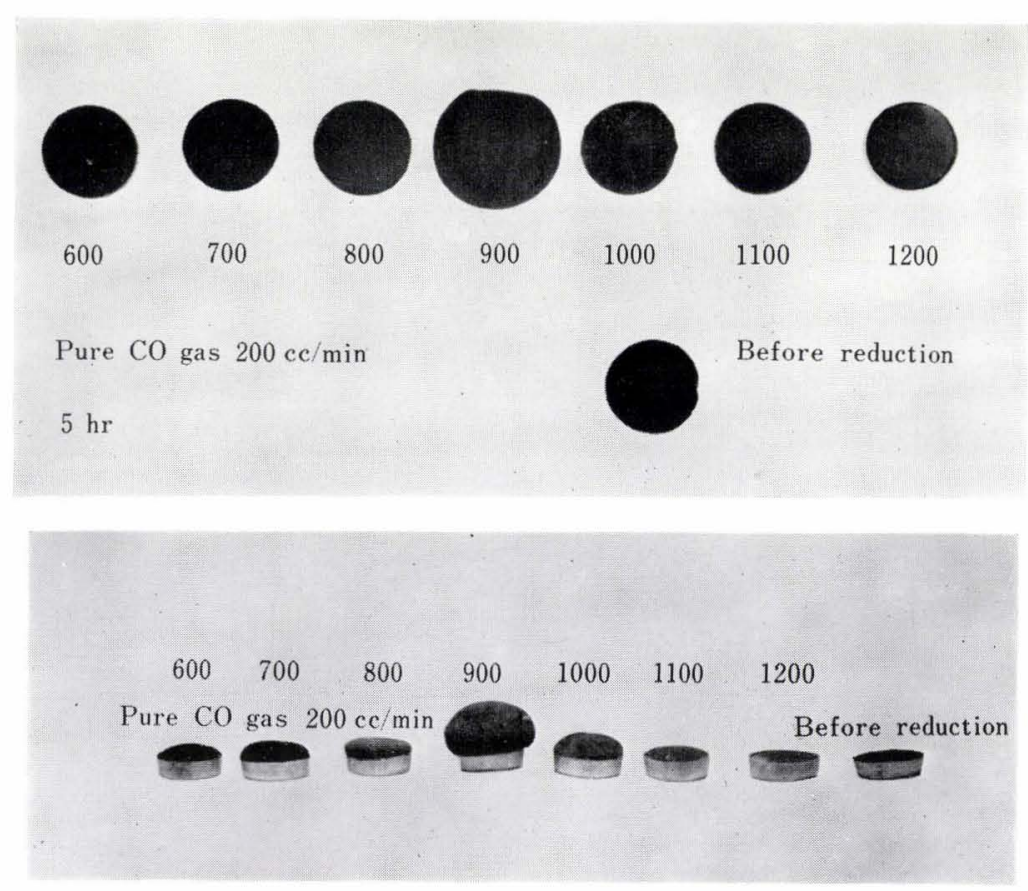

Photo. 1. The cup test for the Marcona pelletizing feed

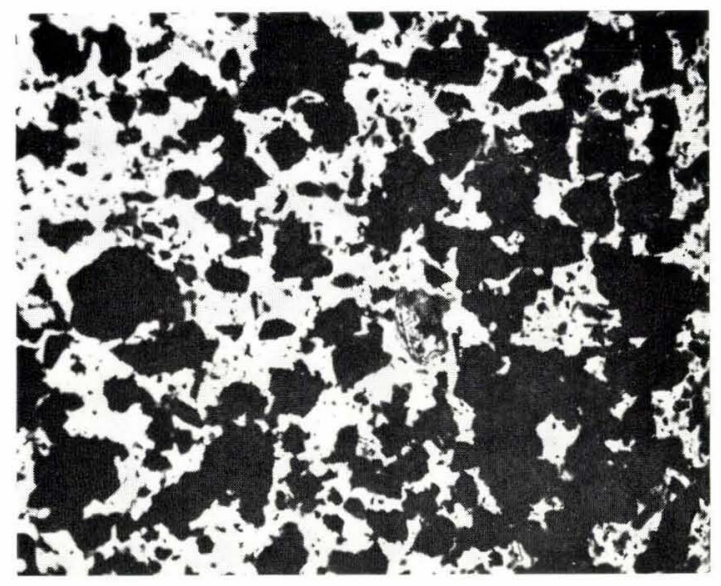

Photo. 2. Marcona pelletizing feed (before reduction) $(\times 100)$ $(2 / 3)$

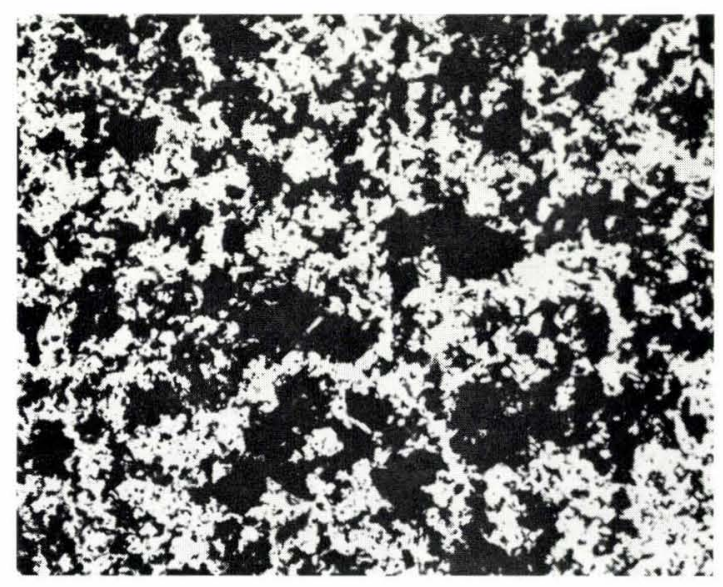

Photo. 3. Marcona pelletizing feed (CO $200 \mathrm{cc} / \mathrm{min}, 800^{\circ} \mathrm{C}$, $5 \mathrm{hr})(\times 100)(2 / 3)$

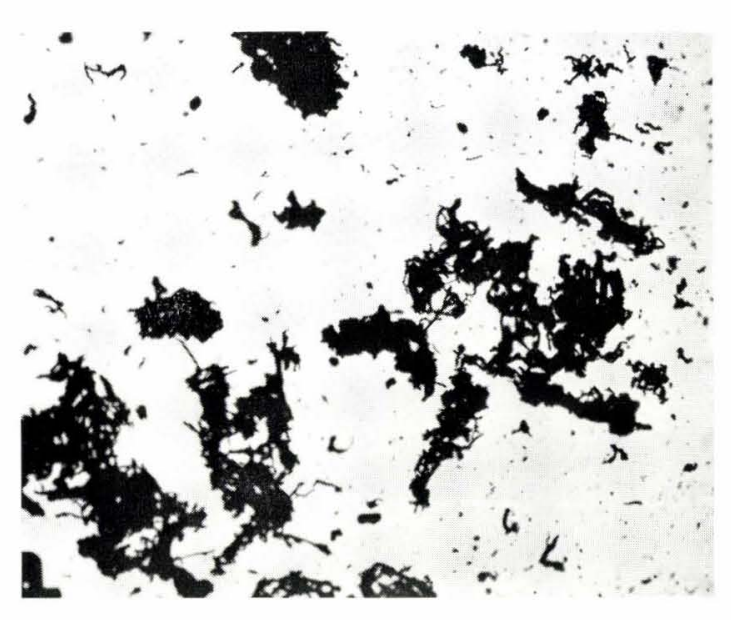

Photo. 4. Marcona pelletizing feed (CO $200 \mathrm{cc} / \mathrm{min}, 900^{\circ} \mathrm{C}$, $5 \mathrm{hr})(\times 100)(2 / 3)$

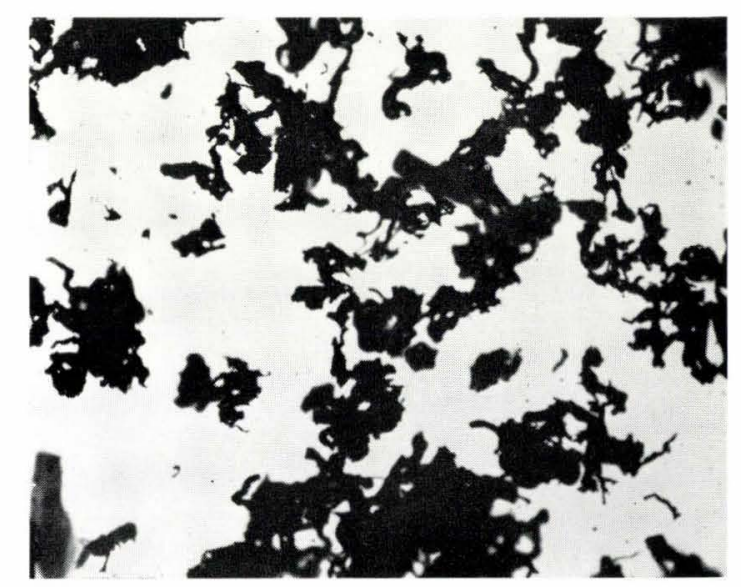

Photo. 5. Marcona pelletizing feed $\left(\mathrm{CO} 200 \mathrm{cc} / \mathrm{min}, 1000^{\circ} \mathrm{C}\right.$, $5 \mathrm{hr})(\times 100)(2 / 3)$ 
ency was observed for the swollen bulk to shrink because of sintering as shown in Photos. 6, 7, and 11.

The results of the cup test for the Marcona pellet, as shown in Fig. 10, were just the same as the results obtained in the vertical reaction tube.

The reason why the maximum swelling temperature

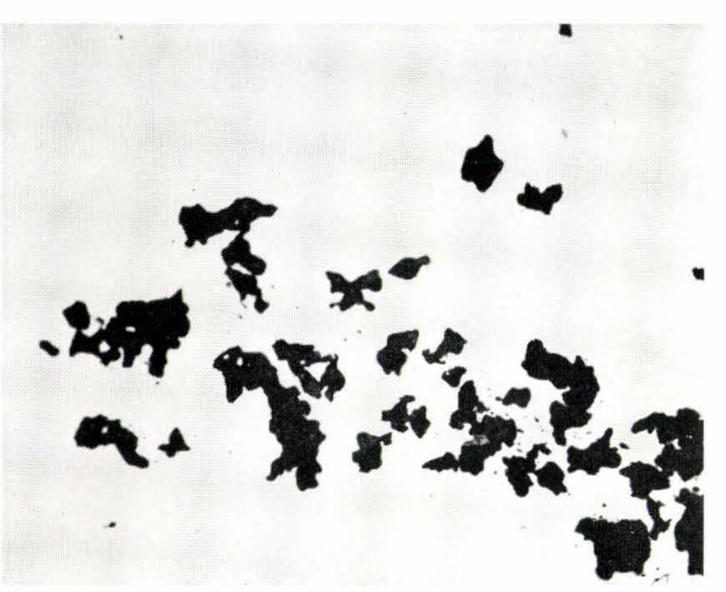

Photo. 6. Marcona pelletizing feed $\left(\mathrm{CO} 200 \mathrm{cc} / \mathrm{min}, 1100^{\circ} \mathrm{C}\right.$, $5 \mathrm{hr})(\times 100)(2 / 3)$

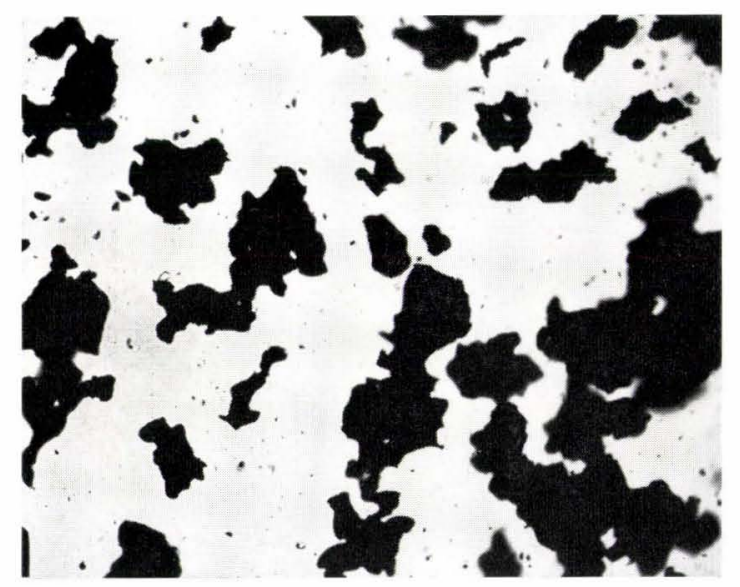

Photo. 7. Marcona pelletizing feed (CO $200 \mathrm{cc} / \mathrm{min}, 1200^{\circ} \mathrm{C}$, $5 \mathrm{hr})(\times 100)(2 / 3)$

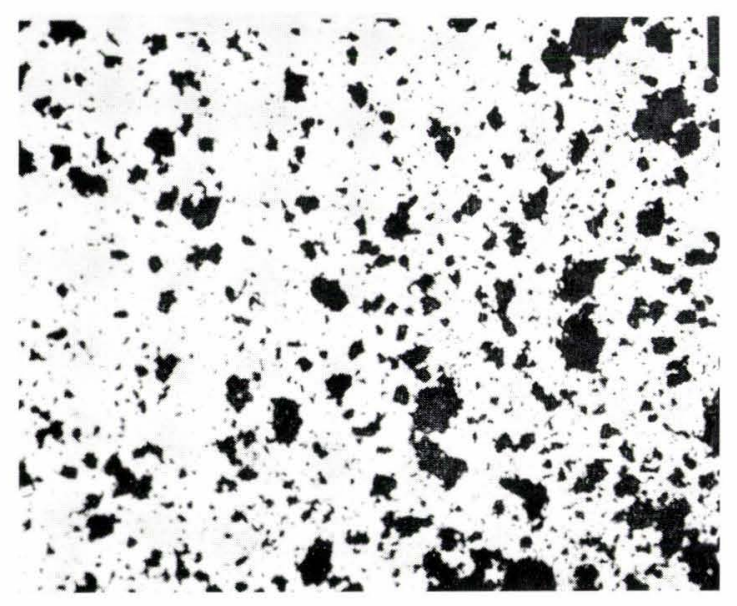

Photo. 8. Marcona pellet (CO $\left.100 \mathrm{cc} / \mathrm{min}, 800^{\circ} \mathrm{C}, 4 \mathrm{hr}\right)(\times 100)$ $(2 / 3)$ is shifted is considered to be the difference of bonding strength among grains against the swelling force by the deforming of the grains. It might be easier to swell unsintered grains rather than for sintered grains at lower temperature under the same reducing condition. According to microscopic observation of the reduced

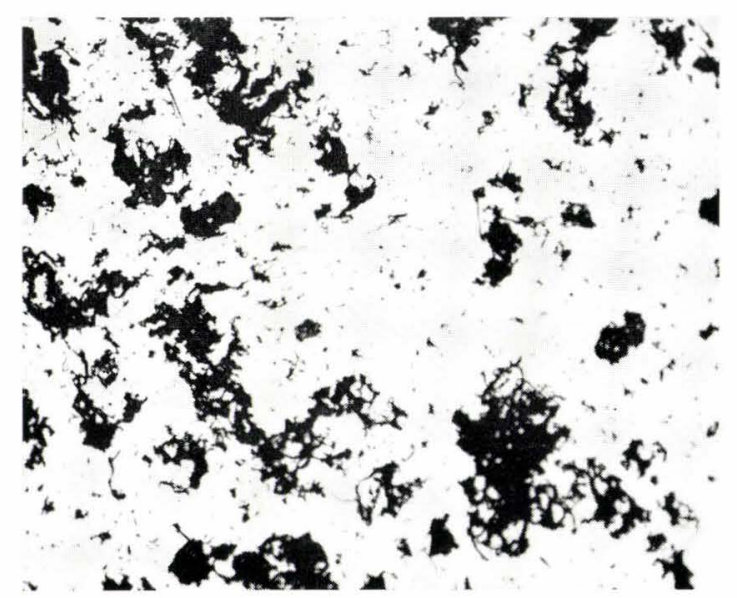

Photo. 9. Marcona pellet $\left(\mathrm{CO} 100 \mathrm{cc} / \mathrm{min}, 900^{\circ} \mathrm{C}, 4 \mathrm{hr}\right)(\times 100)$ $(2 / 3)$

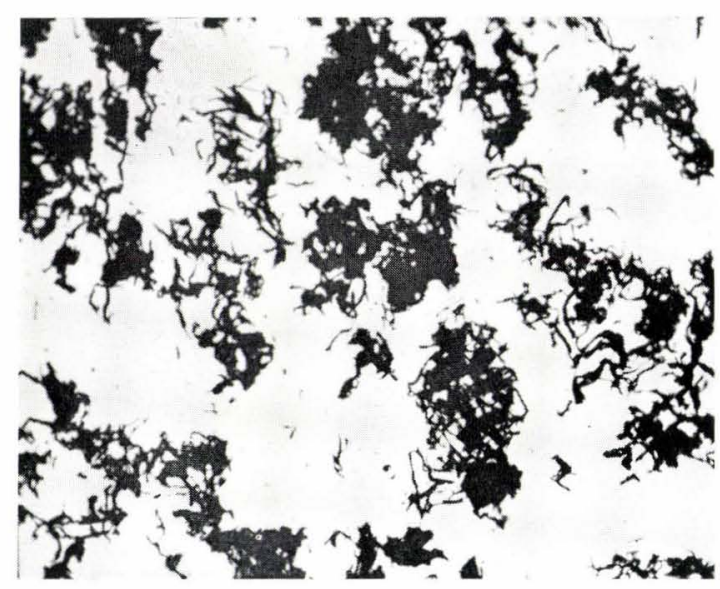

Photo. 10. Marcona pellet (CO $100 \mathrm{cc} / \mathrm{min}, 1000^{\circ} \mathrm{C}, 4 \mathrm{hr}$ ) $(\times 100)(2 / 3)$

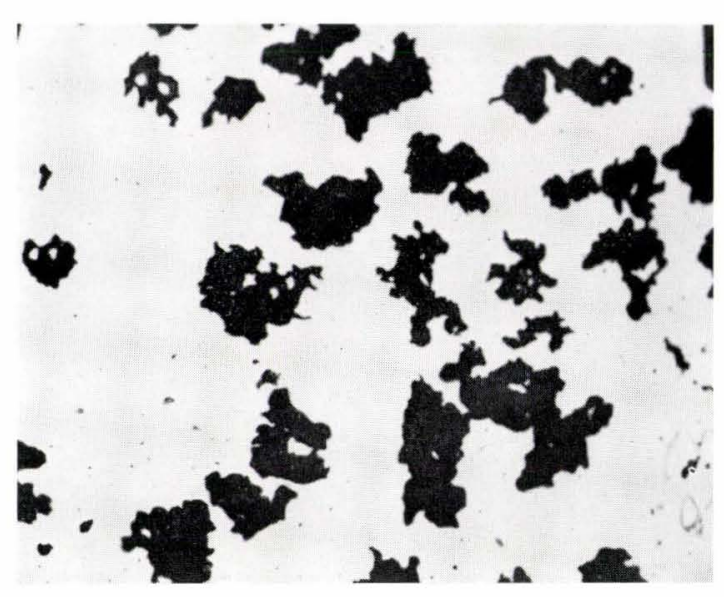

Photo. 11. Marcona pellet (CO $100 \mathrm{cc} / \mathrm{min}, 1100^{\circ} \mathrm{C}, 4 \mathrm{hr}$ ) $(\times 100)(2 / 3)$ 
pelletizing feed at $600^{\circ} \mathrm{C}$, it seemed to leave the shape of the original grain with little change though it was reduced to metallic iron. In the picture of the reduced pelletizing feed at $700^{\circ}$ and $800^{\circ} \mathrm{C}$ (Photo. 3), a little fibrous metallic iron appears from grains. In the reduced pelletizing feed at $900^{\circ}$ and $1000^{\circ} \mathrm{C}$, the initial shape of original grains disappears and deforms to fibrous metallic iron as shown in Photos. 4 and 5, in which fine fibrous iron at $900^{\circ} \mathrm{C}$ aggregates to thicker fibrous form at $1000^{\circ} \mathrm{C}$. In the reduced pelletizing feed at $1100^{\circ}$ and $1200^{\circ} \mathrm{C}$, fibrous iron decreases and sinters together as Photos. 6 and 7 show.

Exactly the same tendency was observed in the pellets reduced at $600^{\circ} \sim 1200^{\circ} \mathrm{C}$ as shown in Photos. $8\left(800^{\circ} \mathrm{C}\right), 9\left(900^{\circ} \mathrm{C}\right), 10\left(1000^{\circ} \mathrm{C}\right)$, and $11\left(1100^{\circ} \mathrm{C}\right)$.

These results show that the magnitude of swelling corresponds to the occurrence and growth of fibrous metallic iron, and that extraordinary swelling of the Marcona pellet and feed as large as $200 \sim 400 \%$ of the initial state is caused by growth of fibrous metallic iron.

On the other hand, microscopic observation of the reduced pellets remaining in the state of magnetite and of wüstite shows that initial shape of grains does not much change without fibrous shape.

In order to catch the initial state and growth of fibrous metallic iron, 100 150 mesh Marcona pelletizing feed was used for the cup test. The feed was reduced in the $\mathrm{CO}$-stream at $900^{\circ} \mathrm{C}$ for one hour. Then the sample was taken from the center of differ-

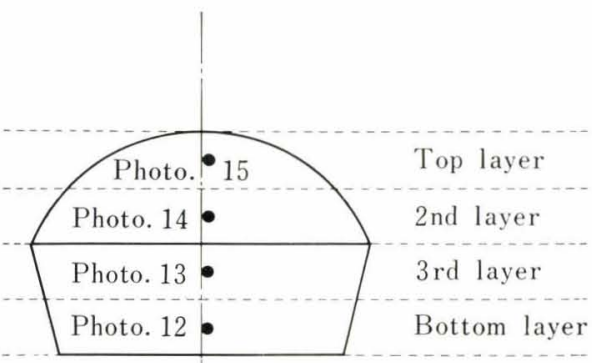

Fig. 11. Location of sample taken in reduced pelletizing feed

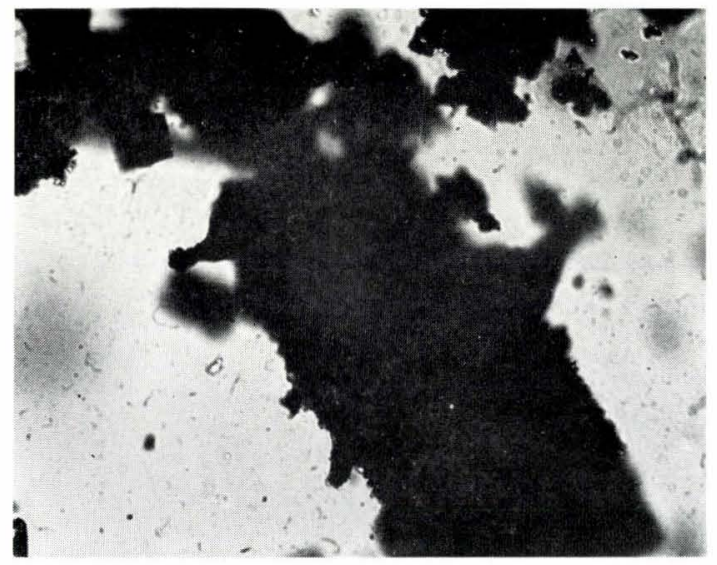

Photo. 12. Marcona pelletizing feed taken from bottom layer (CO $\left.200 \mathrm{cc} / \mathrm{min}, 900^{\circ} \mathrm{C}, 1 \mathrm{hr}\right)(\times 100)(2 / 3)$ ent layers as Fig. 11 shows, and Photos. 12, 13, 14, and 15 of layers from bottom to top show the growth of fibrous metallic iron.

Effect of the size of grain on the apparent volume change was studied. Marcona pelletizing feed has the size distribution as shown in Fig. 4, and was classified into fractions of 60 mesh and over, $60 \sim 100$ mesh, $100 \sim$ 150 mesh, 150 200 mesh, 200 250 mesh, 250 325 mesh, and under 325 mesh. Each fraction was used

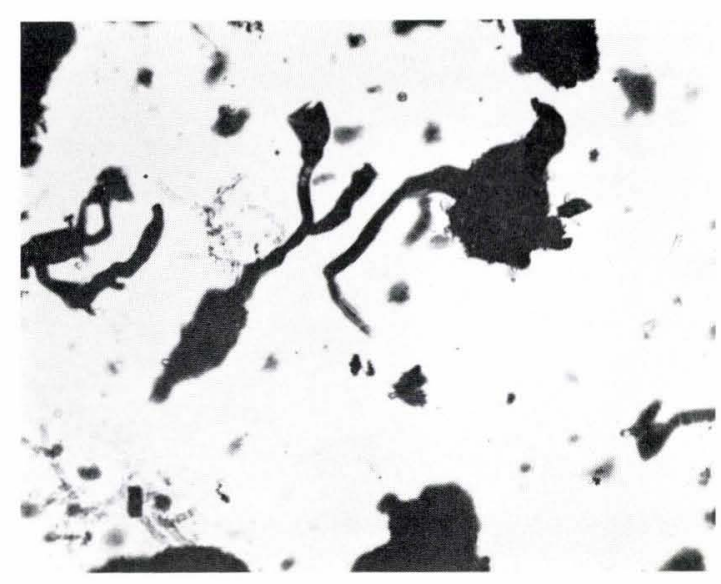

Photo. 13. Marcona pelletizing feed taken from 3rd layer $\left(\mathrm{CO} 200 \mathrm{cc} / \mathrm{min}, 900^{\circ} \mathrm{C}, 1 \mathrm{hr}\right)(\times 400)(2 / 3)$

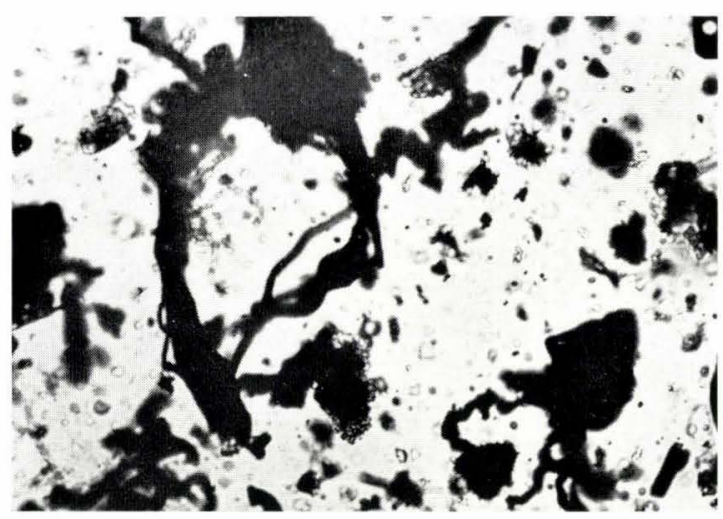

Photo. 14. Marcona pelletizing feed taken from 2nd layer $\left(\mathrm{CO} 200 \mathrm{cc} / \mathrm{min}, 900^{\circ} \mathrm{C}, 1 \mathrm{hr}\right)(\times 400)(2 / 3)$

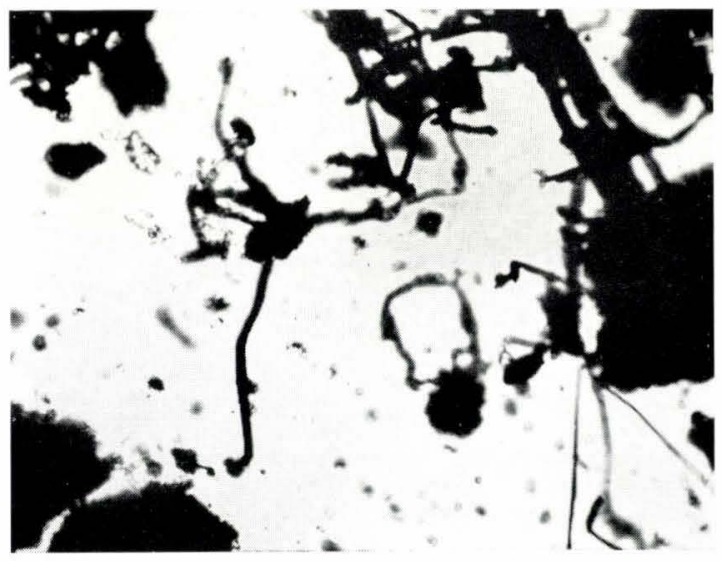

Photo. 15. Marcona pelletizing feed taken from 1st layer (CO $\left.200 \mathrm{cc} / \mathrm{min}, 900^{\circ} \mathrm{C}, 1 \mathrm{hr}\right)(\times 400)(2 / 3)$ 
for the cup test in the $\mathrm{CO}$-stream of $100 \mathrm{cc} / \mathrm{min}$ at $900^{\circ} \mathrm{C}$ for five hours. The results obtained are shown in Fig. 12. The apparent volume change is different depending upon fractions of size of the pelletizing feed. It is large in the range of $150 \sim 325$ mesh, and maximum in $200 \sim 250$ mesh. The fact that a large part of the Marcona pelletizing feed is distributed in these size ranges, which show large apparent volume change, is considered to be a cause of extraordinary swelling of the Marcona pellets. All reduced pelletizing feed becomes completely fibrous metallic iron as shown in Photo. 16 (150 250 mesh) and Photo. 17 (under 325 mesh). Though fibrous iron from the 200 250 mesh feed and the 150 200 mesh feed seems to be a little thicker compared with the others, as a whole, the size of the grains in these ranges before reduction seems to have little relation to the growth of fibrous metallic iron. From time to time big fibrous iron was observed, but in general the fibrous iron is very fine. Most of them are $3 \sim 5 \mu$ thick and $40 \sim 120 \mu$ long. In cases where the feed was reduced at $1000^{\circ} \mathrm{C}$ instead of $900^{\circ} \mathrm{C}$ the length of fibrous iron was not different, $40 \sim 120 \mu$, but its thickness was about $5 \sim 12 \mu$.

As far as the Marcona pellet or the pelletizing feed is reduced by $\mathrm{CO}$, the reduced sample easily becomes fibrous metallic iron, and shows large bulk volume change. However, as Fig. 7 shows, when these samples are reduced by hydrogen, their apparent volume change is not large. In several papers ${ }^{4), 5)}$ it was reported that the Marcona pellet during reduction by hydrogen shows little volume change. However, from Fig. 7 the following tendency could be observed: though the apparent volume change observed was a maximum of $20 \%$, maximum change was apt to occur at about $1000^{\circ} \sim 1100^{\circ} \mathrm{C}$. According to microscopic observation, most of the reduced pellet in hydrogen stream seems not to change initial shape much, but a slight tendency to produce fibrous iron was observed at $1000^{\circ}$ and at $1100^{\circ} \mathrm{C}$ (as shown in Photo. 18).

If the extraordinary swelling occurs in the stage from wüstite to metallic iron during reduction and it is caused by growth of fibrous iron, it could be found in other types of iron oxide. Therefore, as Table 4 shows, the cup test under the conditions of the CO-stream of $100 \mathrm{cc} / \mathrm{min}$ at $900^{\circ} \mathrm{C}$ for five hours was applied to 16 kinds of iron oxide, including hematite, magnetite,

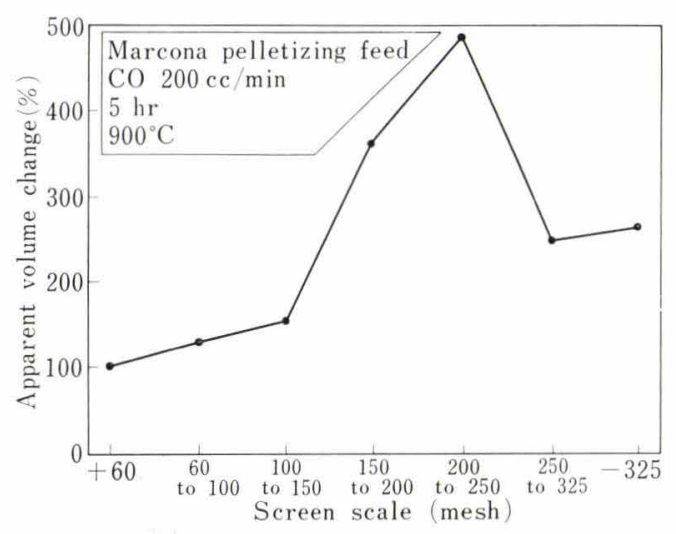

Fig. 12. Effect of size of grain on apparent volume change limonite, and mill scale and chemical reagent. Lump ore was ground to under 100 mesh. Powder form ore was not treated. The sample was filled up in the cup, where bulk density was as close as possible to $2.5 \mathrm{~g} / \mathrm{cm}^{3}$.

As shown in Table 4, most of the oxides after reduction increase their apparent volume, and reduced samples have fibrous metallic iron, though the degrees of volume change are different with the amount of

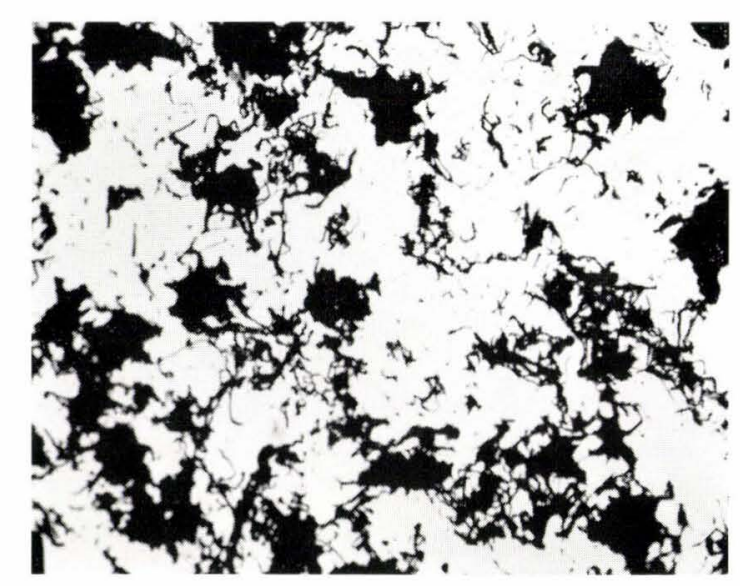

Photo. 16. Marcona pelletizing feed under 150 to 200 mesh $\left(\mathrm{CO} 200 \mathrm{cc} / \mathrm{min}, 900^{\circ} \mathrm{C}, 5 \mathrm{hr}\right)(\times 100)(2 / 3)$

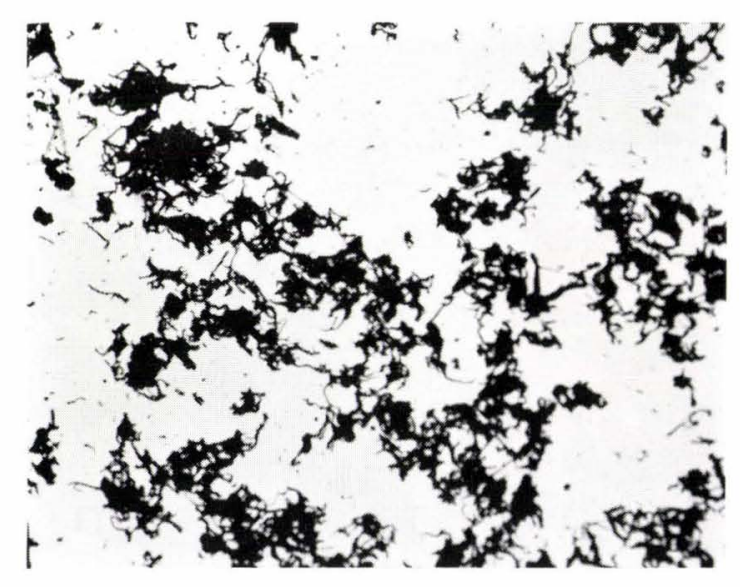

Photo. 17. Marcona pelletizing feed under 325 mesh $\left(\mathrm{CO} 200 \mathrm{cc} / \mathrm{min}, 900^{\circ} \mathrm{C}, 5 \mathrm{hr}\right)(\times 100)(2 / 3)$

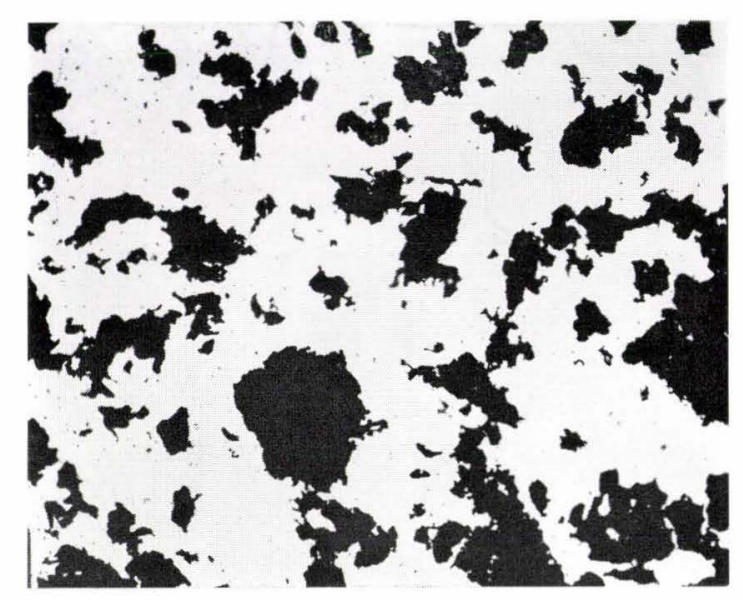

Photo. 18. Marcona pellet $\left(\mathrm{H}_{2} 100 \mathrm{cc} / \mathrm{min}, 1100^{\circ} \mathrm{C}, 4 \mathrm{hr}\right)$ $(\times 100)(2 / 3)$ 
fibrous iron observed. However, hematites from Utah, U.S.A., and from Zungun, Malaysia, and laterite from the Philippines were exceptions. These three did not show fibrous metallic iron and showed little volume change.

Excluding these three among the 16 samples, it was generally observed that the amount of apparent volume change corresponds to the amount of fibrous metallic iron.

From these results obtained, it will be concluded that extraordinary swelling is not a special phenomenon limited only to Marcona pellet or pelletizing feed; it is independent of the geological occurrence or mineralogical origin of iron oxide samples, and it is considered to be a general tendency among iron oxides which do not contain certain kinds of impurities (maybe, as the form of solid solution).

In three kinds of iron ore which do not show the general tendency, there is a common characteristic that alumina contents in them are higher than in others. As the Marcona pellet and feed contain about $0.25 \sim 0.41 \%$ alumina, they were heated up to $1300^{\circ} \mathrm{C}$ and held at $1300^{\circ} \mathrm{C}$ for two hours. Then the cup test was applied to them at $900^{\circ} \sim 1000^{\circ} \mathrm{C}$. As expected, they did not swell and did not show any more fibrous metallic iron. The role played by alumina has been checked by the addition of alumina to Kahlbaum-chemical pure $\mathrm{Fe}_{2} \mathrm{O}_{3}$, which showed large growth of fibrous iron after reduction by $\mathrm{CO}$ (Photo. 19). The series of this work is not yet completed, but so far the results obtained confirm the above conclusion.

The addition of silica to pure iron oxide is also helpful to avoid or decrease swelling.

According to the study of metallic iron whisker, it is easier to get iron whisker from halides. Therefore, the whisker of metallic iron is prepared by reduction of iron ore at $400^{\circ} \sim 900^{\circ} \mathrm{C}$ in hydrogen stream, ${ }^{6)}$ after addition of $\mathrm{NH}_{4} \mathrm{Cl}$ or $\mathrm{FeCl}_{3}$ to iron ore. Marcona pelletizing feed contains $0.3 \% \mathrm{NaCl}$, because sea water has been used for washing at the plant. Therefore, the effect of $\mathrm{NaCl}$ content in feed on the growth of fibrous iron was checked. After the $\mathrm{NaCl}$ content in feed was lowered to $0.08 \%$ by washing, it was applied to the cup test. However, a difference of the amount of fibrous iron after reduction was not observed, as an effect of different content of $\mathrm{NaCl}$.

From the foregoing experimental work, the following conclusions may be drawn with regard to the extraordinary swelling of the Marcona pellet. Carbon deposition is not directly related to abnormal swelling. There is an idea that $\gamma$-hematite will participate in swelling. However, $\gamma$-hematite is unstable above $550^{\circ} \mathrm{C}$, while unusual swelling takes place at temperatures higher than $600^{\circ} \mathrm{C}$. Therefore, the $\gamma$-hematite theory was discarded. Furthermore, $0.3 \% \mathrm{NaCl}$ does not affect swelling.

In order to decrease swelling of the pellet, it is helpful to heat and hold the pellet at $1300^{\circ} \mathrm{C}$, or to add $\mathrm{Al}_{2} \mathrm{O}_{3}$ or $\mathrm{SiO}_{2}$ to pellet feed and heat it at $1200^{\circ} \mathrm{C}$.

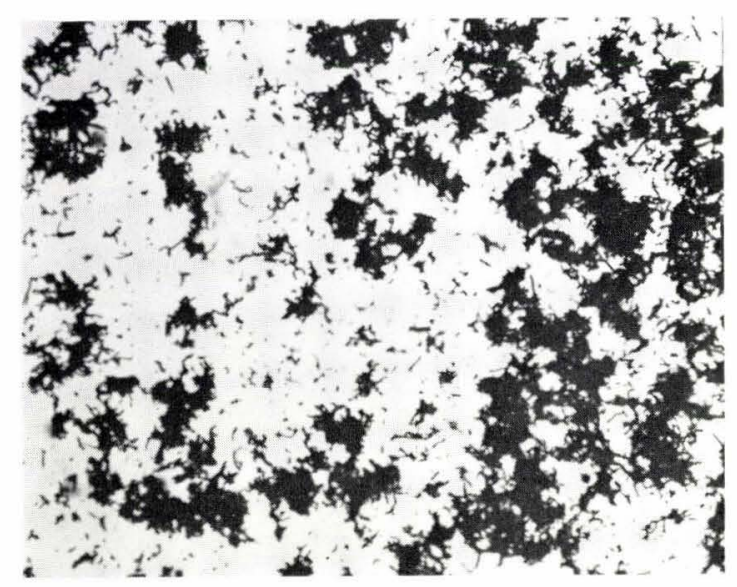

Photo. 19. Kahlbaum-ferric oxide (CO $200 \mathrm{cc} / \mathrm{min}, 900 \mathrm{C}$, $5 \mathrm{hr})(\times 100)(2 / 3)$

Table 4. The cup test for swelling of iron oxides

\begin{tabular}{|c|c|c|c|c|}
\hline Iron oxide & Genesis of deposit & Size for test & $\begin{array}{c}\text { Apparent } \\
\text { volume change } \\
(\%)\end{array}$ & $\begin{array}{l}\text { Growth of fibrous } \\
\text { metallic iron }\end{array}$ \\
\hline Magnetite (Marcona) & Contact metasomatic deposit & Fine grain & 430 & Very large \\
\hline Hematite (Goa) & Residual deposit & -100 mesh & 176 & Large \\
\hline Magnetite (Vancouver) & Contact metasomatic deposit & -100 mesh & 172 & Large \\
\hline Limonite (Kutchan) & Sedimentary iron ore deposit & Fine powder & 103 & Very large \\
\hline Hematite (Anzan) & Contact metasomatic deposit & Fine grain & 100 & Large \\
\hline Mill scale & & -100 mesh & 84.8 & Medium \\
\hline Magnetite (Kamaishi) & Contact metasomatic deposit & -100 mesh & 79.2 & Medium \\
\hline Magnetite (Hangkong) & Contact metasomatic deposit & -100 mesh & 54.0 & Medium \\
\hline Hematite (Johole) & Metasomatic deposit & -100 mesh & 24.2 & Small \\
\hline Iron sand (Tanegashima) & Placer iron ore deposit & -100 mesh & 26.6 & Small \\
\hline Iron sand (Aomori) & Contact metasomatic deposit & -100 mesh & 21.9 & Small \\
\hline Hematite (Utah) & Contact metasomatic deposit & -100 mesh & 17.6 & None \\
\hline Hematite (Dungun) & Residual deposit & -100 mesh & 12.9 & None \\
\hline Laterite & & Fine grain & 3.1 & None \\
\hline $\mathrm{Fe}_{2} \mathrm{O}_{3}$ (Schering-Kahlbaum) & & Fine powder & 88.5 & Very large \\
\hline $\mathrm{Fe}_{2} \mathrm{O}_{3}$ (Junsei) & & Fine powder & 40.1 & Very large \\
\hline
\end{tabular}


Not only the Marcona pellet but also iron oxide which contains little impurities show unusual swelling and growth of fibrous metallic iron.

\section{Discussion}

From Photos. 12 15, the process of formation and growth of fibrous metallic iron could be supposed. As Photo. 12 shows, several rises are observed on the surface of iron ore. And these projections grow while reduction proceeds. Then the original form of the grain disappears with the growth of fibrous iron. These processes could be interpreted on the same basis as C. Wagner ${ }^{7), 8)}$ analyzed the mechanism of the reduction of sulphide to metal.

Wüstite "FeO" is an NaCl-type crystal structure, but in the wüstite range, the $\mathrm{Fe} / \mathrm{O}$ ratio is always somewhat less than the ideal stoichiometric ratio because of the presence of cation vacancy and cations in a higher valence state, i.e. ferric ion. Therefore, the ratio of ferrous ion to ferric ion and the concentration of $\mathrm{O}^{2-}$ are determined by the oxygen potential of the atmosphere around the wüstite. In the process of oxidation and reduction of iron, it is considered that the mobility of ferrous ion is larger compared with the mobility of oxygen ion, and ferrous ion plays a major role in the above reactions. According to Richardson and coworkers, ${ }^{9), 10)}$ the mobility of ferrous ion is affected by temperature and estimated to be about a hundred times larger at above $900^{\circ} \mathrm{C}$ than at $600^{\circ} \mathrm{C}$.

In order to interpret the growth of fibrous metallic iron, the mechanism discussed by C. Wagner in conjunction with the formation of a fine filament of silver during reduction of silver sulphide with hydrogen will be applied.

Figure 13 is the model for the reduction process of wüstite by carbon monoxide. In the first stage of the reduction process at every point on the surface of wüstite, carbon monoxide reacts with oxygen so that excess ferrous ions and electrons are formed and the surface will become supersaturated with respect to ferrous ions and electrons. Though the ferrous ions and electrons migrate in order to form metallic iron, it is necessary for them to be captured by a nucleus at nucleation site on the surface. Ferrous ion and electron in the vicinity of metal nuclei diffuse toward the original nuclei, which are pushed outward by them. Thus fibrous metallic iron grows. The formation of a number of nuclei on the surface will be determined by the nature of the surface, temperature, and the rate of reduction. However, if once nuclei form, supersaturation near the nuclei will be too small to form other nuclei. Therefore, the amount of fibrous iron depends upon the size of grain, the number of nuclei in a grain, the rate of chemical reaction at the surface on the grain, the diffusion coefficient of ion, and the distance from nuclei whose ion should migrate.

According to the results of the reduced pellet in hydrogen stream, as mentioned above, no large growth of fibrous iron was observed. However, from the experimental works by Richardson and co-workers, ${ }^{9), 10)}$ it is possible in principle to reduce iron oxide to fibrous iron with hydrogen, though the reducing conditions are very limited. The results of reduction of $0.01 \mathrm{~mm}$ wüstite film on iron plate with hydrogen by Richardson and his co-workers, were that a very thin film of iron formed on the surface, but its growth soon ceased; then the reduction proceeded outwards from the interface between the iron plate and wüstite. That is, the thickness of the inner iron core increased, instead of metallic iron forming from the surface inward at the outer surface at $900^{\circ} \mathrm{C}$, while spongy metallic iron formed at the outer surface of the wüstite at $700^{\circ} \mathrm{C}$. At $900^{\circ} \mathrm{C}$ ferrous ion and electron diffuse in the layer of wüstite, and metallic iron grows at nuclei on the iron plate just as in the reduction of iron oxide by CO.

Heating the pellet or pelletizing feed or pure iron oxide with the addition of alumina or silica, above $1200^{\circ} \mathrm{C}$, decreases the abnormal swelling of specimen. The observed phenomena will be interpreted that bentonite of a sort, or impurities of iron ore, alumina and silica added diffuse into the surface of iron oxide and disturb the form of nucleus available for nucleation of ferrous ion on the surface of iron oxide.

\section{Conclusion}

The extraordinary swelling of the Marcona pellet which became a serious problem for blast furnace operation, is not the special characteristic of Marcona iron ore or of a pellet made from it. Pure iron oxide has a tendency to grow fibrous metallic iron in process of reduction from wüstite to metallic iron.

In order to avoid the unusually large swelling of the pellet during reduction, it is helpful to reheat the pellet above $1200^{\circ} \mathrm{C}$ if pelletizing feed contains alumina and silica.

\section{Acknowledgements}

The authors express their appreciation to Nippon Kokan K. K., and Yawata Iron \& Steel Co. Ltd. for supplying Marcona pellets and the pelletizing feed respectively. And also they thank Mr. A. B. Virazor, ${ }^{11)}$ Mr. Sia Chun Kit, ${ }^{12)}$ and Mr. K. Matsuda ${ }^{12}$ for their help in experimental work.

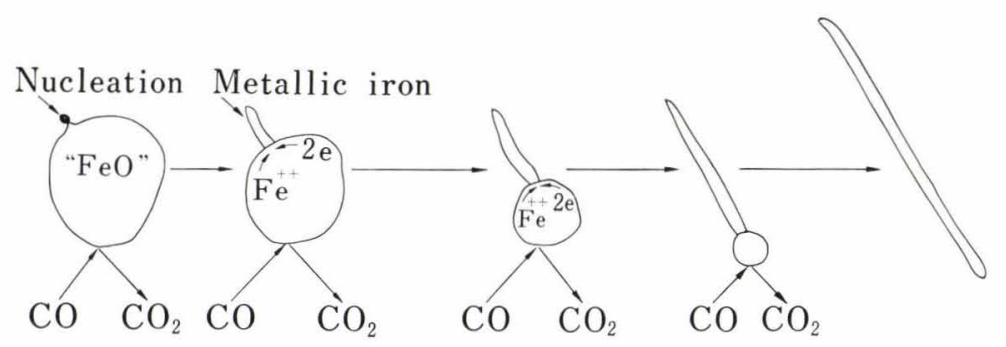

Fig. 13. Model for growth of fibrous iron 


\section{REFERENCES}

1) A. Ishimitsu and K. Sugawara: Tetsu-to-Hagané, 50 (1964), 1888.

2) S. Watanabe and M. Yoshinaga: Tetsu-to-Hagané, 51 (1965), 582.

3) S. Matoba and Y. Ootake: Report of Japan Society for the Promotion of Science, 54th Committee, No. 298, (1954).

4) C. Yoshii : Report of Japan Society for the Promotion of Science, 54th Committee, No. 834, (1964).

5) S. Yagi and Y. Ono: Report of Japan Society for the Promotion of Science, 54th Committee, No. 933, (1965).

6) P. D. Gorsuch : Physical Chemistry of Process Metallurgy,
Part 2 (1959), 771

7) C. Wagner: Trans. AIME, 192 (1952), 214

8) C. Wagner: Steelmaking: The Chipman Conference, (1965), 19.

9) F. D. Richardson and E. Dancy: Disc. Farad. Soc., 4 (1948), 229.

10) O. H. Gellner and F. D. Richardson: Nature, 168 (1951), 23.

11) T. Fuwa and S. Ban-ya: Report of Japan Society for the Promotion of Science, 54th Committee, No. 923 (1965).

12) T. Fuwa, S. Ban-ya, and Sia Chun Kit: Report of Japan Society for the Promotion of Science, 54th Committee, No. 979 (1965). 